\title{
OBSERVATIONS OF GYRFALCONS ALONG THE COLVILLE RIVER, ALASKA, 1981-2005
}

\author{
Ted SWem and Angela Matz
}

\begin{abstract}
US Fish and Wildlife Service, Fairbanks Fish and Wildlife Field Office, 101 12th Avenue, Room 110, Fairbanks, AK 99701,USA.E-mail: ted_swem@fws.gov
\end{abstract}

\begin{abstract}
AвSTRACT.-Gyrfalcons have been studied or monitored along the Colville River in northern Alaska intermittently since 1952 . Work there prior to the mid-1970s was done primarily by Tom Cade and Clayton White, and resulted in numerous well-known publications. Here we present observations of Gyrfalcons collected incidental to Peregrine Falcon monitoring in 23 years between 1981 and 2005. Surveys were collected along a $345 \mathrm{~km}$ stretch from the confluence with the Etivluk River to Ocean Point. Generally, habitat upriver consists of rolling tundra with smaller, discrete rock outcrops along both river banks, while habitat downriver is flat, arctic coastal plain with larger, longer bluffs on only the river's left limit (facing downstream). Survey timing, optimized for Peregrine Falcons, was not optimal for Gyrfalcons and compromised accurate determination of site occupancy, nest success, and the number of young produced at many sites. The number of sites known to be occupied varied from 8-29 among years. Estimated annual production of young ranged from 2-56. Gyrfalcons occupied forty-three discrete cliffs or segments along longer cliffs; these sites were occupied from 1-19 times over the 23 years. These observations are generally in line with historical observations by Cade and White; no long-term trends in abundance or reproductive performance in the region are evident. White morphs comprised about $10 \%$ of the breeding adults on average. Banding over 200 nestlings yielded negligible information on movements. Received 30 April 2011, accepted 25 July 2011.
\end{abstract}

Swem, T., AND A. Matz. 2011. Observations of Gyrfalcons along the Colville River, Alaska, 19812005. Pages 229-236 in R. T. Watson, T. J. Cade, M. Fuller, G. Hunt, and E. Potapov (Eds.). Gyrfalcons and Ptarmigan in a Changing World, Volume I. The Peregrine Fund, Boise, Idaho, USA. http://dx.doi.org/ 10.4080/gpcw.2011.0120

Key words: Alaska, Colville River, occupancy, production, spacing, color morphs, Falco rusticolus.

THERE IS A LONG AND STORIED HISTORY of raptor studies and monitoring in Alaska, including work along the Colville River on Alaska's North Slope. Kessel and Cade (1958) first inventoried the avian community along the Colville River as part of general investigations of the region conducted by the U.S. Navy, and
Cade returned to the Colville in subsequent years as part of his seminal studies of Gyrfalcon (Falco rusticolus) and Peregrine Falcon (F.peregrinus) ecology in Alaska (Cade 1960). White and Cade (1971) further studied the ecology of cliff-nesting raptors, including Gyrfalcons, and Common Ravens (Corvus corax), 
along the Colville River in 1967-1969, building on Cade's earlier work. By the early 1970s, declines in Peregrine populations worldwide (Hickey 1969) caused increased interest in Peregrine and raptor inventories. In response, Cade, White, and colleagues returned to Alaska and the Colville River in the 1970s, conducting extensive aerial and ground surveys to monitor Peregrine populations and further document distribution, population trends, breeding performance, and contaminant exposure of Peregrines and other sympatric raptor species (White and Cade 1971, White and Cade 1975). These efforts cumulatively provided historical observations of Gyrfalcon nesting ecology along the Colville River for at least 8 years between 1952 and 1975 .

In the late 1970s, the US Fish and Wildlife Service (Service) organized and coordinated broad-scale Peregrine monitoring efforts within Alaska. These efforts, conducted by a broad consortium of governmental and nongovernmental organizations and individuals, combined extensive surveys to document abundance of raptors within the state, with intensive monitoring of Peregrine populations primarily in four "index areas" that contained significant numbers of nesting Peregrines and a history of earlier surveys. By virtue of the earlier work by Cade, White, and others which provided a backdrop for subsequent observations, the Service identified the Colville River as a Peregrine monitoring index area, and the Bureau of Land Management and Service collaborated to support and conduct annual raptor surveys along the river. The surveys were designed to monitor trends in the abundance, productivity, and contaminant loads of Peregrines, and to the extent possible, were conducted using standardized effort, timing, and methodology. Although the surveys were designed and timed to focus on Peregrines, observations of other raptor species, including Gyrfalcons, were collected incidentally.

Here we report observations of Gyrfalcon occupancy and reproduction along the Colville
River collected incidental to Peregrine monitoring surveys during the interval 1981-2005. We limit our reporting to 23 breeding seasons for which we believe that the effort, methods, and observations recorded were sufficiently consistent to allow comparison among years.

\section{Study AREA}

The Colville River is the largest river on Alaska's North Slope, draining an area of approximately $64,000 \mathrm{~km}^{2}$. Observations were made along the Colville River from the confluence with the Etivluk River to Ocean Pt (elevations 260 and $26 \mathrm{~m}$, respectively), a distance along the river's course of approximately 350 $\mathrm{km}$. Within this stretch, about 80 cliffs and bluffs occur, varying from about 5 to $165 \mathrm{~m}$ in height and from $5 \mathrm{~m}$ to $8 \mathrm{~km}$ in length. In general, nesting sites upriver (above Umiat, comprising $230 \mathrm{~km}$ along the river's course) occur on both limits of the river, and on relatively small, discrete bluffs, which often are widelyspaced. In contrast, downriver (below Umiat, comprising $120 \mathrm{~km}$ along the river's course) nesting sites are exclusively on the left limit, and generally occur on dirt banks, many of which are continuous for several kilometers and accompany the river for approximately $60 \%$ of its course in this stretch. The cliffs and bluffs used by Gyrfalcons are generally comprised of poorly consolidated sediments, but are highly variable in their structure. They also varied in the availability of overhangs, under which Gyrfalcons often nested, and the presence of nesting ravens, which often built the structures that Gyrfalcons later co-opted for their own use. More detailed descriptions of the region and habitat can be found in Kessel and Cade (1958), Cade (1960), and White and Cade (1971).

\section{MethodS}

Twice each year, we floated downriver through the entire study area in an inflatable raft with an outboard engine. Each float took 14-20 days, and was made by two observers. The 
first float took place approximately 15 June to 4 July, which coincided with the early- to midnestling stage for Gyrfalcons; the second float took place approximately 15 July to 3 August, which coincided with the late-nestling to early post-fledging stage. During each float, all cliffs and bluffs were searched for the presence of Gyrfalcons and evidence of nesting. Small cliffs close to the river were checked from the boat; those too large or distant from the river were checked by walking along the base or top. Sites were considered occupied if one or more Gyrfalcons were present during either float. Pairs were considered to be nesting if eggs, young, incubation, or brooding was seen during either float.

We developed two indices of breeding performance. Total production of young within the study area, hereafter referred to as the "number of young," was estimated based on the number of young and/or fledglings seen in or near nests. Due to the disparity in the ages of young at the time of nest visits, and the fact that many young fledged between the first and second floats, the number of young at each nest was usually ascribed based on the number of nestlings present during the first float. In cases where we felt confident that the nest failed between the first and second floats, or that the number of young decreased between floats, the number of young ascribed to that site was based on the number alive during the second float. Average breeding performance, hereafter referred to as the "number of young per site," was calculated as the number of young, described above, divided by the number of occupied sites. The occasional sites where we saw Gyrfalcons but were unable to reliably determine their breeding status or outcome were not included in this calculation.

Nest site locations are provided as both "cliff number" (following the convention of White and Cade 1971, who identified and enumerated 80 cliffs downstream from the mouth of the Etivluk River to Ocean Pt) and "river kilome- ter" (following US Fish and Wildlife Service raptor survey convention, starting at the river's headwaters and proceeding downriver to the mouth) to allow comparison with previous reports. Inter-site spacing was calculated as linear distance between/among nests (which reflects the distance along the bluffs), not along the winding course of the river.

Nestlings were banded in a subset of nests in 1981-1995, using standard US Fish and Wildlife Service/US Geological Survey bands.

\section{RESUlTS}

Gyrfalcons occupied 42 different sites between 1981 and 2005, with an average of 15 sites occupied per year (range 8-29, Table 1). In most cases, occupied sites were known to contain pairs, as either a pair or nest with eggs or young was observed, but at some sites only a single adult and no occupied nest was observed. There was no trend over time in the number of occupied sites (Pearson $r=-0.07$, $\mathrm{p}=0.75)$.

The 42 individual sites were occupied from 119 times in 23 years (mean 8.1). Thirteen (31\%) were occupied 1-4 times; nine (21\%) were occupied 5-8 times; 13 (31\%) were occupied 9-12 times; 3 (7\%) were occupied 13-16 times; and $4(10 \%)$ were occupied $>17$ times.

The greatest frequency of use and closest spacing among occupied sites generally occurred in the middle reaches of the river, from just upstream to just downstream from Umiat (cliff number 53-63, river $\mathrm{km} \mathrm{476-536).} \mathrm{There,} 10$ sites were occupied 128 times (average c. 13 times in 23 years per site; average 5.5 sites occupied per year), and accounted for $38 \%$ of total occupied sites observed. Four of these sites were occupied in $>16$ years. Elsewhere along the river, the remaining 32 sites were occupied 211 times (average $c .7$ times in 23 years per site; average $c .9$ sites occupied per year). 
Table 1. Abundance and productivity, 1981-2005, for Gyrfalcons along the Colville River, Alaska.

\begin{tabular}{|c|c|c|c|c|c|c|c|c|c|c|c|c|}
\hline Parameter & 1981 & 1982 & 1983 & 1984 & 1985 & 1986 & 1987 & 1988 & 1989 & 1990 & 1991 & 1992 \\
\hline $\begin{array}{l}\text { Total number of } \\
\text { occupied sites }\end{array}$ & 20 & 12 & 14 & 8 & 16 & 9 & 12 & 21 & 15 & 29 & 22 & 17 \\
\hline Number of young & 19 & 5 & 26 & 6 & 33 & 12 & 27 & 28 & 32 & 56 & 19 & 9 \\
\hline Number of young/site & 1 & & 2 & & 2.2 & & 2.25 & 1.4 & 2.13 & 1.89 & 1.58 & 0.56 \\
\hline $\begin{array}{l}\text { Percent of sites with } \\
\text { young }\end{array}$ & 53 & 33 & 77 & & & & 83 & 65 & 80 & 72 & 45 & 31 \\
\hline Parameter & 1993 & 1994 & 1995 & 1996 & 1997 & 1998 & 1999 & 2000 & 2001 & 2002 & 2005 & \\
\hline $\begin{array}{l}\text { Total number of } \\
\text { occupied sites }\end{array}$ & 13 & 12 & 14 & 11 & 13 & 13 & 16 & 18 & 22 & 9 & 10 & \\
\hline Number of young & 2 & 7 & 22 & 14 & 29 & 13 & 16 & 7 & 9 & 5 & 17 & \\
\hline Number of young/site & 0.16 & 0.87 & 1.69 & 2.33 & 2.42 & 1.5 & 1.23 & 0.7 & 0.6 & 0.62 & 1.9 & \\
\hline $\begin{array}{l}\text { Percent of sites with } \\
\text { young }\end{array}$ & 15 & 25 & 62 & 54 & 85 & 54 & 54 & 57 & 40 & 38 & 80 & \\
\hline
\end{tabular}

In this same $50 \mathrm{~km}$ interval near Umiat, 2-10 sites were occupied annually, for a minimum average spacing of about one occupied site per $5.5 \mathrm{~km}$ when all 10 sites were occupied (as in 1990). The closest spacing (also in 1990) was among seven occupied sites in $27 \mathrm{~km}$ and five occupied sites in $15 \mathrm{~km}$ (average linear spacing of 4.6 and $4.1 \mathrm{~km}$, respectively).

A substantial number of Gyrfalcons were found in the lower reaches of the river. We found 122 of $339(36 \%)$ nests and 14 of 42 $(34 \%)$ sites used in $33 \%$ of the survey route downriver from Umiat Mountain (cliff 57, km $498)$, with $41(12 \%)$ nests below cliff $61, \mathrm{~km}$ 530 in the lowest $24 \%$ of the survey route.

The number of young thought to be produced varied from 2-56 per year (mean 19.1 per year; $\mathrm{n}=21$ years), and the number of young per site also varied considerably, from 0.16 to 2.42 (mean 1.9 per occupied site; $\mathrm{n}=21$ years) (Table 1). The number of occupied sites per year was not correlated with the number of young per site (Pearson $r=-0.102, \mathrm{p}=0.669)$.
While there was a slight decrease in the number of young per occupied site over time, it was not significant (Pearson $r=-0.26, \mathrm{p}=0.26$ ).

Our "presence" data, where adult Gyrfalcons were detected, generally represented Gyrfalcons that had viable nests (young were seen at $83 \%$ of 226 territories where one or two adults were detected on the first check and $74 \%$ of 104 territories where one or two adults were detected during the second check). In addition to occasionally finding adults that had no viable nests (the balance of the occupied territories enumerated above), we also found young at some territories where no adults were seen $(9 \%$ of 207 nests on the first check; $38 \%$ of 124 nests during the second check).

White morph individuals formed a small and variable proportion of the adult Gyrfalcons at occupied breeding sites. White adults were seen at breeding sites in 19 of $22(86 \%)$ years, and the average annual proportion of white morphs within all adult Gyrfalcons seen at 
nesting sites was 0.10 (range zero to 0.27 ). No black morphs were seen in any year.

We banded 208 nestling Gyrfalcons in 13 breeding seasons; only one was subsequently recovered. A nestling banded in Killik Bend in 1988 was trapped along with a juvenile Gyrfalcon in a fox snare (baited with a duck wing) in April 1993 along the Sagavanirktok River, approximately $210 \mathrm{~km}$ ENE of the banding location.

\section{Discussion}

We observed considerable inter-annual variation in estimates of territory occupancy and breeding performance. The high inter-annual variation we observed along the Colville River is generally consistent with earlier observations from the Colville River (Cade 1960, White and Cade 1971, White and Cade 1975, Swem et al. 1994), and elsewhere in in North America (Poole and Bromley 1988, Mossop and Hayes 1994, Swem et al. 1994) and the Old World (Nielsen 1986). Within the large variation we observed, we detected no significant temporal trends in Gyrfalcon territory occupancy or breeding performance along the Colville River.

We feel it is important to mention shortcomings in our methods that likely imparted measurement error into our estimates of territory occupancy and breeding performance. Our surveys were timed poorly for Gyrfalcons. Our first visit to territories took place during the early nestling stage for most Gyrfalcon pairs, and our second visit roughly coincided with fledging. Thus, neither visit conformed to recommended raptor survey protocols which suggest that the first survey, generally used to document territory occupancy, take place near the time of egg-laying, and the second visit, used to document the production of young, take place before fledging (Steenhof 1987, Steenhof and Newton 2007). It is almost certain that our late first visit to territories resulted in our missing some non-breeding and early- failed pairs, which would result in under-estimation of abundance and over-estimation of productivity. Further, each of our surveys spanned at least 16 days, while inter-pair breeding chronology also varied by at least several weeks, so there was at least 26 day variation among pairs in the stage of nesting at the time of the same territory visit. Our suboptimal timing confounded with large interpair differences in chronology likely decreased the accuracy and precision of our estimates.

Our methods also do not allow for a numeric estimate of detection probability, which likely varies among years (depending on breeding propensity and success), between first and second surveys, and with factors such as cliff size, the visibility of individual nest sites, and presence of an occupied nest. Implementation of standardized methods, such as those of Booms et al. $(2010,2011)$ for aerial raptor surveys in southwest Alaska, would be necessary. Although we checked each territory twice each year, we did not conduct repeated visits to Gyrfalcon territories during the same stage of reproduction, which would allow for reasonable estimates of detection.

White and Cade (1971) found Gyrfalcons using 21 different sites in 1967-1969, compared to 40 and 69 used by Peregrine Falcons and Rough-legged Hawks (Buteo lagopus), respectively. With the benefit of more years of observation, we have found Gyrfalcons occupying 42 different sites, whereas Peregrine Falcons and Rough-legged Hawks each used over 100 sites (T. Swem pers. obs.), consistent with White and Cade's (1971) supposition that Gyrfalcons have more specific nesting habitat requirements than the other co-occurring species. The distribution of Gyrfalcons along the river may have shifted from historical to contemporary periods, however. White and Cade (1971) noted that Gyrfalcons only rarely nested downriver from Umiat Mountain (cliff

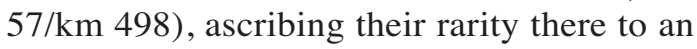
absence of firm rock and overhangs to nest beneath. In 1967-1969, only 5 of 31 (16\%) 
nests and 3 of $21(14 \%)$ sites used were downriver from Umiat Mountain, and no nests were found downriver from cliff $61 / \mathrm{km} 530$. We found more nests downriver from Umiat Mountain. At this time, we are unsure whether this represents population growth, a shift in distribution along the river, or intermittent use of less-optimal sites.

Cade (1960) originally noted that white Gyrfalcons may breed along Alaska's Bering Sea coast, but found no evidence of white Gyrfalcons breeding on the North Slope. A photo of a white male breeding along the Colville River was later published by White and Cade (1971), though they made no mention in the accompanying text of the prevalence of white morphs in the breeding population during their work in the 1960s. In our observations, white morphs were present in the Colville River breeding population in most years. We find it unfortunate that information on color morphs of Gyrfalcons has not been typically mentioned in publications regarding the species in Alaska. Further, given the desirability of white Gyrfalcons to falconers, birders and photographers alike, we recommend that the State of Alaska, which manages falconry harvest in Alaska, explicitly state as a management objective that the naturally-occurring distribution of various color morphs of the Gyrfalcon be maintained.

\section{ACKNOWLEDGMENTS}

We thank Tom Cade and Clay White for their friendship and mentoring, and for pioneering raptor study and conservation in Alaska's Arctic. We are also grateful to 32 fellow biologists who traveled with us and and helped us collect observations and feed mosquitoes. We thank the following people for the use of their observations: Bob Dittrick and Lisa Moorehead (1983); Ken Riddle and Phil Schempf (1984); and Jim Silva and Roy Masinton (1986). We would also like to thank Rick Watson, Grainger Hunt, and Terry Hunt, who provided very useful edits on the original manuscript.

\section{Literature Cited}

Booms, T. L, P. F. SCHEMPF, B. J. MCCAFFERY, M. S. LindBERG, AND M. R. FulLer. 2010. Detection probability of cliff-nesting raptors during helicopter and fixed-wing aircraft surveys in western Alaska. Journal of Raptor Research 44:175-187.

Booms, T. L, P. F. SCHEMPF, B. J. MCCAFFERY, M. S. LindBERG, AND M. R. FULlER. 2011. Detection probability of Gyrfalcons and other cliff-nesting raptors during aerial surveys in Alaska. Extended abstract in R. T. Watson, T. J. Cade, M. Fuller, G. Hunt, and E. Potapov (Eds.). Gyrfalcons and Ptarmigan in a Changing World. The Peregrine Fund, Boise, Idaho, USA. DOI 10.4080/gpcw.2011.0124

CAde, T. J. 1960. Ecology of the Peregrine and Gyrfalcon populations in Alaska. University of California Publications in Zoology 63:151-290.

Hickey, J. J. 1969. Peregrine Falcon Populations: Their Biology and Decline. University of Wisconsin Press, Madison, Wisconsin, USA.

KESSEL, B., AND T. J. CADE. 1958. Birds of the Colville River, Northern Alaska. Biological Papers of the University of Alaska 2:1-83.

Mossop, D. H., AND R. HAYES. 1994. Long-term trends in the breeding density and productivity of gyrfalcon Falco rusticolus in the Yukon Territory, Canada. Pages 403-413 in B.- U. Meyburg, and R. D. Chancellor (Eds). Raptor conservation today: proceedings of the IV world conference on birds of prey and owls World Working Group on Birds of Prey and Owls, London, UK.

NiELSEN, O. K. 1986. Population ecology of the Gyrfalcon in Iceland, with comparative notes on the Merlin and the Raven. Ph.D. dissertation, Cornell University, Ithaca, New York, USA.

PoOle, K. G., AND R. G. BRomley. 1988. Interrelationships within a raptor guild in the central Canadian Arctic. Arctic 41:31-38.

STEENHOF, K. 1987. Assessing raptor reproductive success and productivity. Pages 157- 
170 in B. A. Giron Pendleton, A. A. Millsap, K. W. Cline, and D. M. Bird (Eds). Raptor Management Techniques Manual. National Wildlife Federation, Washington, DC, USA. SteEnhof, K., AND I. Newton. 2007. Assessing nesting success and productivity. Pages 181-192 in D. M Bird and K. L. Bildstein (Eds). Raptor Research and Management Techniques. Hancock House, Surrey, British Columbia, Canada.

Swem, T., C. McIntyre, R. J. Ritchie, P. J Bente, And D. G. Roseneau. 1994. Distribution, abundance, and notes on the breeding biology of Gyrfalcons Falco rusticolus in Alaska. Pages 437-444 in Meyburg, B.U. and R. D. Chancellor (Eds). Raptor
Conservation Today: Proceedings of the IV World Conference on Birds of Prey and Owls. World Working Group on Birds of Prey and Owls, London, UK.

White, C. M., AND T. J. CADE. 1971. Cliffnesting raptors and ravens along the Colville River in arctic Alaska. Living Bird 10:107-150.

White, C. M., AND T. J. CADE. 1975. Raptor studies along the proposed Susitna powerline corridors, oil pipeline, and in the Yukon and Colville River regions of Alaska. Unpubl. Report to US Fish and Wildlife Service, Bureau of Land Management, and National Park Service, Arctic Gyrfalcons on Colville River, Alaska. 
- Swem ANd Matz - 